Check for updates

Cite this: RSC Adv., 2019, 9, 37079

Received 19th September 2019

Accepted 1st November 2019

DOI: 10.1039/c9ra07613a

rsc.li/rsc-advances

\section{Patterned films of a hybrid lead halide perovskite grown using space-confined conversion of metallic lead by reactive polyiodide melts}

\author{
Aleksei Y. Grishko, ${ }^{a}$ Andrey A. Petrov, (iD a Eugene A. Goodilin ${ }^{\text {abc }}$ \\ and Alexey B. Tarasov (iD *ab
}

A unique technique for preparation of thin patterned perovskite films is suggested based on an interaction of reactive polyiodide melts with metallic lead coatings using a patterned die with a given relief. The growth of perovskite in confined space results in pin-hole free textured films.
Perovskite photovoltaics has experienced tremendous growth since 2009, when Miyasaka used $\mathrm{MAPbI}_{3}\left(\mathrm{MA}=\mathrm{CH}_{3} \mathrm{NH}_{3}{ }^{+}\right)$as a sensitizer in a DSSC and obtained the efficiency of $3.6 \% .{ }^{1}$ In less than 10 years, perovskite solar cells have reached the efficiency of $25.2 \%$ (ref. 2 ) and proved to be a competitor to silicon and thin-film solar cells. Texturing of the light-absorbing layer in a solar cell can greatly improve its efficiency due to optimization of light-scattering ${ }^{3}$ and, in particular increase the efficiency of silicon-perovskite tandems up to $25.5 \% .^{4-6}$ Simulation studies suggest large improvement of the efficiencies for the nanopatterned perovskite films ${ }^{7-10}$ that was also confirmed experimentally. ${ }^{\mathbf{1 1}}$

The variety of approaches to obtained patterned films include etching ${ }^{\mathbf{1 2 , 1 3}}$ and micro-structuring ${ }^{\mathbf{1 4}}$ of the substrate, sacrificial template synthesis, crystallization from the solution under the stamp, ${ }^{15}$ and direct deformation of perovskite layer by molding. ${ }^{16}$ While substrate surface modification only allows to texture bottom side of the perovskite film, other approaches result in texturing of the top side of the perovskite film.

Recently, a new precursor with the formula $\mathrm{MAI}_{x>3}$ coined as reactive polyiodide melts (RPM) was discovered which converts metallic lead films into high-quality large-area $\mathrm{MAPbI}_{3}$ films $^{17,18}$ through a simple reaction: $\mathrm{MAI}_{3}+\mathrm{Pb} \rightarrow \mathrm{MAPbI}_{3}$ without any byproducts. In this report, we realize this reaction under confined space conditions between metallic lead coating and a patterned die thus developing a new method for fabrication of hybrid perovskite thin films with a flexibly controlled surface pattern.

As a key solution, a droplet of RPM was deposited onto a plastic die with a striped relief and squeezed between the die

${ }^{a}$ Laboratory of New Materials for Solar Energetics, Department of Materials Science, Lomonosov Moscow State University, Lenin Hills, 119991 Moscow, Russia. E-mail: alexey.bor.tarasov@yandex.ru

${ }^{b}$ Department of Chemistry, Lomonosov Moscow State University, 1 Lenin Hills, 119991 Moscow, Russia

${ }^{c}$ Kurnakov Institute of General and Inorganic Chemistry, 31 Leninsky Prospekt, 119992, Moscow, Russia and the thin film of metallic lead to initiate reactive confined growth of a hybrid perovskite layer. In our study we used a commercially available polyethylene terephthalate diffraction grating with $500 \mathrm{~nm}$ width and $280 \mathrm{~nm}$ depth of the stripes therefore providing the confined volume of $14000 \mu \mathrm{m}^{3}$ per 1 $\mathrm{cm}^{2}$ of the die. We demonstrate that constraining of the RPM to the free volume between surfaces of the die and the metallic lead film allows to achieve a desired final morphology of the perovskite $\mathrm{MAPbI}_{3}$ film. The control over the shape of the die thus provides a convenient way to fabricate perovskite films with a given relief.

The interplay between absorption and charge collection by the electron- and hole-transporting layers requires the perovskite layer to be $300-800 \mathrm{~nm}$ thick ${ }^{9,19}$ for the maximum performance of the solar cell. The molar volume of hybrid perovskite $\mathrm{MAPbI}_{3}$ is 8.3 times larger than that of metallic lead, therefore $35-100 \mathrm{~nm}$ of metallic lead is sufficient to form dense perovskite layer of the desired thickness.

We developed a new approach that allows a precise dosing of RPM that is based on the interaction of RPM with lead. We achieve this by pressing the die with a given relief containing RPM deposited onto it against the metallic lead film as depicted in Fig. 1.

When a die is brought into physical contact with the metallic lead film, the RPM is immediately distributed over the whole substrate. In this implementation $\mathrm{RPM} / \mathrm{Pb}$ reagent ratio is determined by the volume of the RPM between the die with a relief and the substrate. Because of the large difference in molar volumes of $\mathrm{CH}_{3} \mathrm{NH}_{3} \mathrm{PbI}_{3}$ and $\mathrm{Pb}$, the interface between the growing perovskite film and the die develops tangentially to the surface. Once the perovskite crystallization front reaches the surface of the die, its vertical growth gets blocked and the lateral growth starts. This ensures full coverage of the substrate and exact replication of the die relief by the as-formed perovskite film. Moreover, at the stage of lateral growth, the excess of RPM is pushed away from the space between the die and the perovskite film by the growing 

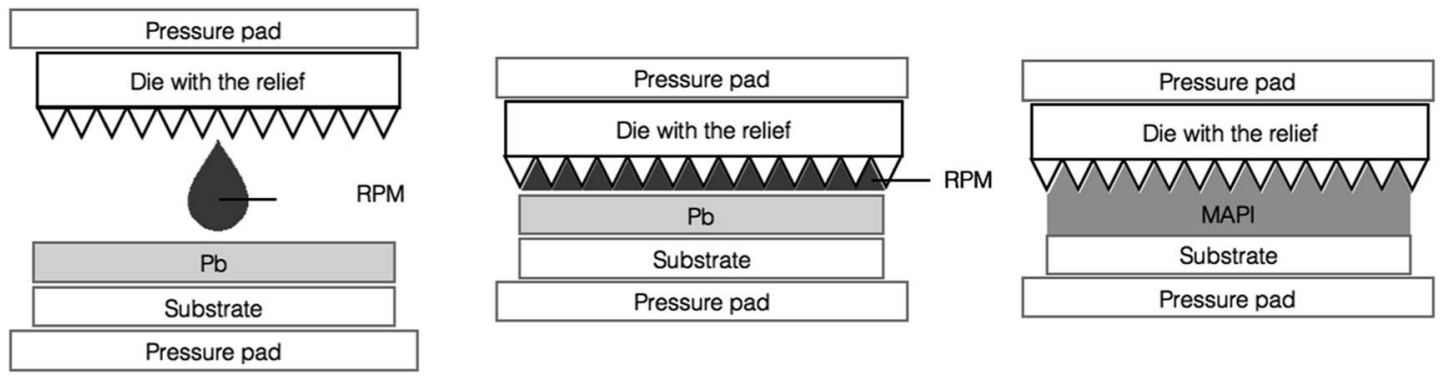

Fig. 1 The scheme of the fabrication of the perovskite thin films using the space-confined conversion of metallic lead with RPM.

perovskite grains. By optimizing the exposure time of the metallic lead film to RPM before pressing the die against it, we obtained single-phase perovskite films (Fig. 2d) with a thickness of $\sim 800 \mathrm{~nm}$. The typical morphology of the perovskite films fabricated under space-confined conditions is shown in Fig. 2a-c. One can see that this film consists of $\sim 300-1000 \mathrm{~nm}$ size perovskite grains which completely cover the substrate. The relief of the perovskite film obtained by this method replicates the die which demonstrates that an arbitrary relief can be transfered to the final perovskite film.

Moreover, we discovered that the high concentration of the RPM components and high recrystallization ability of the MAI- $\mathrm{I}_{2}$ system allows modification of the surface relief of the perovskite films obtained by other methods. In order to exemplify this approach, we obtained a perovskite film using conversion of metallic lead by RPM under free growth conditions with consequent rinsing with isopropyl alcohol (Fig. 3a). Then we pressed the die with the relief with a thin layer of RPM on it against the as-prepared perovskite film, waited for 10 minutes, washed an excess of RPM with isopropyl alcohol and disassembled the reaction pair. The morphology of the film adopted the morphology of the die and appeared to be exactly the same as the one obtained using space-confined growth (Fig. $3 \mathrm{~b}$ ).

Thus, high concentration of the components in the RPM allows for the vertically confined growth and ensures high
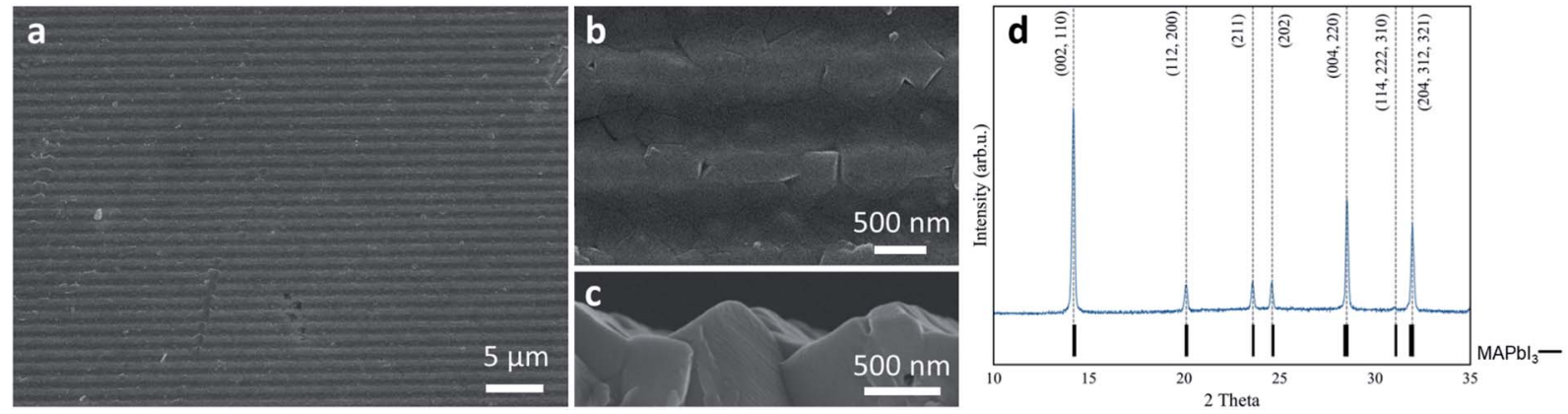

Fig. 2 SEM images $(a-c)$ and XRD (d) of the film obtained by space-confined growth method.
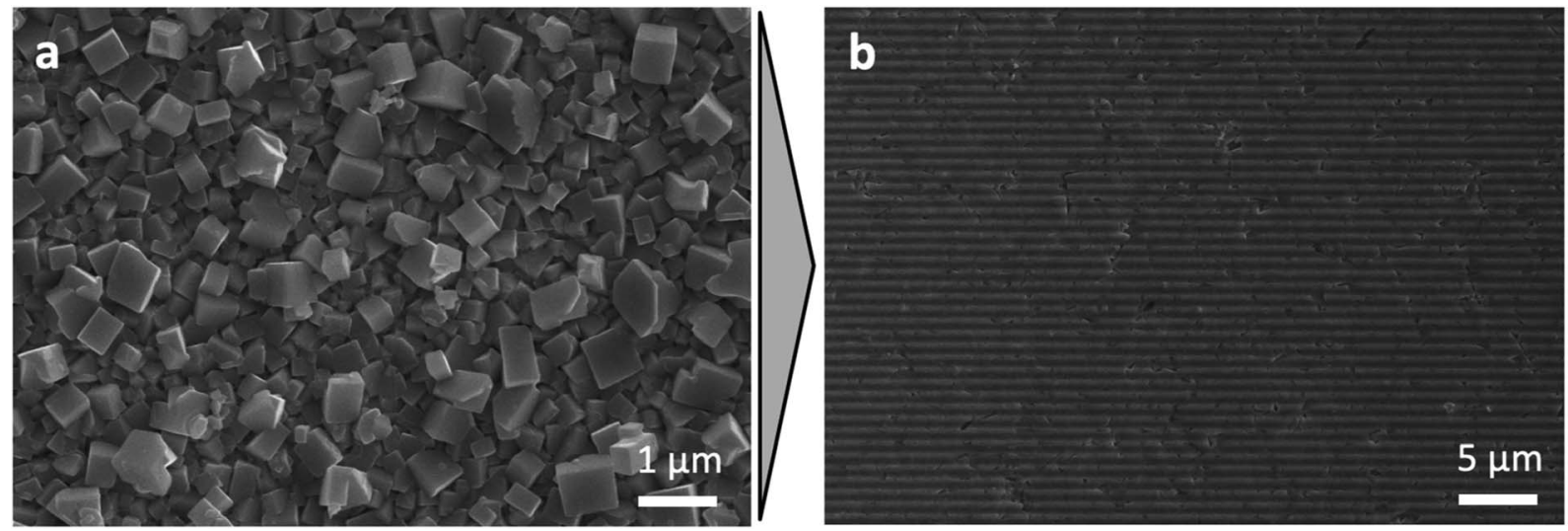

Fig. 3 SEM images of the perovskite film before (a) and after (b) recrystallization in the confined space launched by pressing the die with a relief with a thin layer of RPM on it against that film. 
recrystallization ability of the RPM which make it possible to transfer the relief of the die to the perovskite film. The preparation of a single-phase perovskite in the form of largecrystalline film with a surface relief using the novel confined growth approach makes it possible to scale up the process of solar perovskite production and allows for new techniques that add recently unavailable flexibility to the process of fabrication of solar cells. In addition, further applications of artificial reliefs would allow to develop texturing procedures due to the effect of graphoepitaxy ${ }^{20}$ and also have a potential of providing higher efficiency of light harvesting by lower reflectivity on patterned light absorbing surfaces.

\section{Experimental part}

Thin metallic lead films (35-100 nm) were deposited by means of thermal evaporation in vacuum $\left(10^{-5}\right.$ torr $)$. Reactive polyiodide melts were prepared by mixing powders of $\mathrm{CH}_{3} \mathrm{NH}_{3} \mathrm{I}$ and $\mathrm{I}_{2}(1: 2 \mathrm{~mol})$ at room temperature. In order to convert thin films of metallic lead into perovskite films, a droplet of the asprepared melt was deposited onto the surface of the die with a striped relief (PET diffraction grating with 1000 lines per $\mathrm{cm}$ was used as a die) that was squeezed against thin film of metallic lead. Die was held in contact with the substrate for 5-10 minutes to ensure the complete conversion. Excess of the melt was washed away from the exterior of the reaction cell by excessive amount of isopropyl alcohol.

X-ray powder diffraction data was obtained on Bruker D8 Advance, morphology of thin films was examined by means of Zeiss Supra 40 scanning electron microscope.

\section{Conflicts of interest}

There are no conflicts to declare.

\section{Acknowledgements}

Authors are grateful to the Development Program of Lomonosov Moscow State University.

\section{References}

1 A. Kojima, K. Teshima, Y. Shirai and T. Miyasaka, J. Am. Chem. Soc., 2009, 131, 6050-6051.

2 Best Research-Cell Efficiencies (NREL), accessed Oct 29, 2019.
3 K. X. Wang, Z. Yu, V. Liu, Y. Cui and S. Fan, Nano Lett., 2012, 12, 1616-1619.

4 G. Nogay, F. Sahli, J. Werner, R. Monnard, M. Boccard, M. Despeisse, F.-J. Haug, Q. Jeangros, A. Ingenito and C. Ballif, ACS Energy Lett., 2019, 4, 844-845.

5 M. Jošt, E. Köhnen, A. B. Morales-Vilches, B. Lipovšek, K. Jäger, B. Macco, A. Al-Ashouri, J. Krč, L. Korte, B. Rech, R. Schlatmann, M. Topič, B. Stannowski and S. Albrecht, Energy Environ. Sci., 2018, 11, 3511-3523.

6 H. Kanda, N. Shibayama, A. Uzum, T. Umeyama, H. Imahori, K. Ibi and S. Ito, ACS Appl. Mater. Interfaces, 2018, 10, 3501635024.

7 Z. Xie, S. Sun, W. Wang, L. Qin, Y. Yan, R. Hou and G. G. Qin, Opt. Commun., 2018, 410, 117-122.

8 J. van Deelen, Y. Tezsevin and M. Barink, MRS Adv., 2017, 2, 3091-3098.

9 W. E. I. Sha, X. Ren, L. Chen and W. C. H. Choy, Appl. Phys. Lett., 2015, 106, 221104.

10 Z. Xie, S. Sun, X. Xie, R. Hou, W. Xu, Y. Li and G. G. Qin, Semicond. Sci. Technol., 2018, 33, 015011.

11 X. Yang, J. Wu, T. Liu and R. Zhu, Small Methods, 2018, 2, 1800110.

12 F. Wang, Y. Zhang, M. Yang, L. Fan, L. Yang, Y. Sui, J. Yang and X. Zhang, Nano Energy, 2019, 60, 198-204.

13 D. I. Kim, S.-H. Nam, K.-H. Hwang, Y.-M. Lee and J.-H. Boo, Funct. Mater. Lett., 2016, 09, 1642011.

14 R. T. Ginting, E.-B. Jeon, J.-M. Kim, W.-Y. Jin and J.-W. Kang, ACS Appl. Mater. Interfaces, 2018, 10, 31291-31299.

15 M. E. Kamminga, H. H. Fang, M. A. Loi, G. H. Ten Brink, G. R. Blake, T. T. M. Palstra and J. E. Ten Elshof, ACS Appl. Mater. Interfaces, 2018, 10, 12878-12885.

16 H. Wang, R. Haroldson, B. Balachandran, A. Zakhidov, S. Sohal, J. Y. Chan, A. Zakhidov and W. Hu, ACS Nano, 2016, 10, 10921-10928.

17 A. A. Petrov, N. A. Belich, A. Y. Grishko, N. M. Stepanov, S. G. Dorofeev, E. G. Maksimov, A. V. Shevelkov, S. M. Zakeeruddin, M. Graetzel, A. B. Tarasov and E. A. Goodilin, Mater. Horiz., 2017, 4, 625-632.

18 I. Turkevych, S. Kazaoui, N. A. Belich, A. Y. Grishko, S. A. Fateev, A. A. Petrov, T. Urano, S. Aramaki, S. Kosar, M. Kondo, E. A. Goodilin, M. Graetzel and A. B. Tarasov, Nat. Nanotechnol., 2019, 14, 57-63.

19 D. Liu, M. K. Gangishetty and T. L. Kelly, J. Mater. Chem. A, 2014, 2, 19873-19881.

20 E. A. Goodilin, E. S. Reddy, J. G. Noudem, M. Tarka and G. J. Schmitz, Phys. C, 2002, 372-376, 842-845. 